\title{
Aspectos morfológicos da tuba uterina de cutias (Dasyprocta aguti, Mammalia: Rodentia)
}

Eunice Anita de Moura FORTES ${ }^{1}$;

Maria Acelina Martins de CARVALHO²;

Mônica Marcos de ALMEIDA ${ }^{1}$;

Aírton Mendes CONDE JÚNIOR ${ }^{1}$;

Nádia Expedita de Almeida CRUZ1;

Antônio Chaves de ASSIS$\mathrm{NETO}^{3}$

\section{Corespondência para:}

MARIA ACELINA MARTINS DE

CARVALHO

Departamento de Morfofisiologia

Veterinária

Centro de Ciências Agrárias

Universidade Federal do Piauí

Campus Agrícola da Socopo

64049-550 - Teresina - PI

mcelina@ufpi.br

carvalhomam@uol.com.br

Recebido para publicação: 17/06/2003 Aprovado para publicação: 15/03/2005

1- Departamento de Morfologia, Centro de Ciências da Saúde, Universidade Federal do Piauí, Teresina - PI

2- Departamento de Morfofisiologia Veterinária, Centro de Ciências

Agrárias, Universidade Federal do Piauí, Teresina - PI

3- Faculdade de Zootecnia da Univesidade Estadual Paulista, Campus de Dracena, Dracena - SP

\section{Resumo}

Foi analisada a estrutura da tuba uterina de cutias utilizando-se três fêmeas adultas, oriundas do Núcleo de Estudos e Preservação de Animais Silvestres da Universidade Federal do Piauí. Após anestesia, foi realizada a eutanásia dos animais, em seguida, obtidos fragmentos da tuba uterina correspondentes às regiões cranial, média e caudal. Cortes de 3 a $5 \mathrm{~m}$ de espessura foram corados pela Hematoxilina/Eosina e analisados e fotografados ao microscópio de luz. Foi evidenciado que, a parede da tuba uterina da cutia apresenta três camadas histologicamente distintas: mucosa, muscular e serosa, caracterizando as regiões infundíbulo, ampola e istmo. A mucosa, revestida por tecido epitelial simples colunar apresentando células ciliadas e não ciliadas, e, com grande quantidade de pregas em diferentes níveis. No epitélio de revestimento da mucosa do istmo, foram observadas áreas com células variando de cúbicas a pavimentosas. A luz do órgão, nas porções cranial e média, mostrase bem maior e mais irregular que na porção caudal. A lâmina própria, constituída de tecido conjuntivo frouxo, desprovida de glândulas, e na região da ampola, torna-se mais estreita e bastante celularizada. A camada muscular, formada por fibras musculares lisas dispostas em uma subcamada circular interna e outra longitudinal externa. A serosa mostra-se bastante vascularizada. As tubas uterinas da cutia guardam muita semelhança com as dos demais mamíferos quanto aos aspectos microscópicos.

\section{Introdução}

\begin{abstract}
Pesquisas envolvendo animais da fauna brasileira vêm crescendo acentuadamente nesses últimos anos. Esses estudos estão centrados, na maioria das vezes, na importância para a preservação de algumas espécies, assim como, na produção de alimentos e de rendimentos ou, ainda na busca de modelos alternativos para pesquisas experimentais.
\end{abstract}

A cutia, roedor de porte médio, um pouco menor que a paca, apresenta-se como importante componente da nossa fauna. Se adapta facilmente ao cativeiro, se reproduzindo sem dificuldades nessas condições ${ }^{1}$.

Estudos sobre a morfologia dos órgãos reprodutivos desses roedores são escassos na literatura, no entanto, constituem-se de grande relevância pois, contribuem para otimizar a produção e a reprodução, além de possibilitar o estabelecimento de parâmetros que possam caracterizá-los como modelo biológico para pesquisas laboratoriais. Assim, este trabalho objetivou analisar, as características histológicas da tuba uterina de cutias, tendo 
em vista a importância desse órgão, pelas funções que desempenha, especialmente, no transporte de gametas e embriões, visando contribuir com novas biotécnicas na reprodução de roedores.

De acordo com a maioria dos autores consultados, a tuba uterina dos mamíferos, apresenta três segmentos morfologicamente distintos: o infundíbulo, extremidade cranial, com fímbrias na sua borda livre; ampola, alargada e o istmo, segmento estreito que se une ao corno uterino na junção uterotubária ${ }^{2,3,4,5,6}$. Essa divisão não é tão visível, anatomicamente, em todas as espécies ou em todas as fases do ciclo ${ }^{4}$. Para Gartner e Hiatt ${ }^{7}$; Junqueira e Carneiro ${ }^{8}$ esse órgão apresenta quatro regiões anatômicas, acrescentando, a intramural, extremidade fixa que atravessa a parede uterina se abrindo na luz do útero.

Informações específicas sobre a morfologia da tuba uterina em roedores mostram que, na capivara essa estrutura apresenta-se delgada, muito convoluta e incorporada à bolsa ovárica (OJASTI, 1973 apud SILVA; PERDOMO, 1983). $\mathrm{Na}$ maioria dos histricomorfos, conforme Weir e Rowlands ${ }^{9}$ a porção do infundíbulo da tuba uterina, apresenta inúmeras circunvoluções, e fímbrias que recobrem parcialmente os ovários, sendo que, no seu terço final, torna-se reta e estreita. Para Almeida et al. ${ }^{10}$ estudando o gerbil da Mongólia (Meriones unguiculatus) a tuba uterina, histologicamente, mostra-se como um longo e tortuoso ducto tubular, com quatro regiões distintas e consecutivas: intramural, istmo, ampola e infundíbulo.

Trabalhando com cutias, Araújo et al. ${ }^{11}$, Guimarães, Matos e Vale ${ }^{12}$, afirmam que a tuba uterina desses roedores é bastante longa e apresenta numerosas circunvoluções. Acrescentam os primeiros autores, comprimento médio para essa estrutura, de $6,43 \mathrm{~cm}$ à direita e $6,15 \mathrm{~cm}$ à esquerda.

Microscopicamente, a tuba uterina dos mamíferos em geral, incluindo os roedores, encontra-se organizada em três camadas distintas: o revestimento interno, a mucosa, constituída por epitélio simples colunar com células ciliadas e não ciliadas, secretoras, e a lâmina própria de tecido conjuntivo frouxo; uma média, a muscular, com duas camadas sendo uma, circular interna e uma longitudinal externa; a serosa, lâmina de peritônio visceral, formando o revestimento externo do órgão $\mathrm{O}^{2,3,5,6,7,8,13,14,15,16}$. Afirmam Almeida et al. ${ }^{10}$ que no gerbil da Mongólia, a tuba uterina apresenta semelhanças anatômicas e histológicas com a dos roedores usados como animais de laboratório.

$\mathrm{Na}$ projeção do istmo na cavidade uterina do coipo (Myocastor coypus), observase 3 a 4 pregas mucosas, revestidas por epitélio simples cúbico, a camada muscular circular mantém-se individualizada da túnica homóloga do útero ${ }^{14}$.

Trabalhos sobre os aspectos histológicos da tuba uterina da cutia não foram evidenciados na literatura, o que também motivou a realização do presente estudo.

\section{Materiais e Métodos}

Esta pesquisa foi realizada no Laboratório de Anatomia Animal do Centro de Ciências Agrárias da Universidade Federal do Piauí. Foram utilizadas três cutias fêmeas, adultas, procedentes do Núcleo de Estudos e Preservação de Animais Silvestres da Universidade Federal do Piauí, em Teresina, PI.

Os animais foram anestesiados (associação de acepromazina + tiletamina/ zolazepan), em seguida, foi realizada a eutanásia. Posteriormente, obtidos fragmentos das tubas uterinas correspondentes à região cranial, próxima ao ovário, ao terço médio e ao terço caudal, próximo ao corno uterino. Esses fragmentos foram fixados em solução de formaldeído a $10 \%$ (tampão de $\mathrm{NaOH} 0,1 \mathrm{~N}$ ) por um período não inferior a 48 horas, em seguida, o material foi destinado à rotina histológica para a inclusão em parafina, à microtomia para a obtenção de cortes de 3 a $5 \mathrm{~m}$ de 
espessura e submetidos à técnica de coloração pela Hematoxilina/Eosina (HE). A análise das preparações e as fotomicrografias para documentação, foram realizadas em microscópio de luz (Olympus BX41).

\section{Resultados, Discussão e Conclusão}

A tuba uterina da cutia apresenta-se longa, delgada e bastante convoluta, de acordo com as observações de Araújo et al. ${ }^{11}$, Guimarães, Matos e Vale ${ }^{12}$; na capivara conforme (OJASTI, 1973 apud SILVA, PERDOMO, 1983); na maioria dos histricomorfos $^{9}$ e no gerbil da Mongólia ${ }^{10}$. Evidencia-se nesse órgão, as regiões do infundíbulo, ampola e istmo, (Figura 1) confirmando os dados da literatura para a maioria das espécies domésticas e silvestres. Especificamente, para roedores, os achados de Weir e Rowlands ${ }^{9}$ na maioria dos histricomorfos; no Myocastor coypus s.14. $^{13,}$. Almeida et al. ${ }^{10}$ apontam quatro regiões distintas na tuba uterina do gerbil da Mogólia, incluindo uma porção intramural. Do mesmo modo, Gartner e Hiatt ${ }^{7}$; Junqueira e Carneiro $^{8}$, acrescentando que, este segmento intramural, representa a parte do istmo que penetra na parede do útero terminando no óstio uterino da tuba.

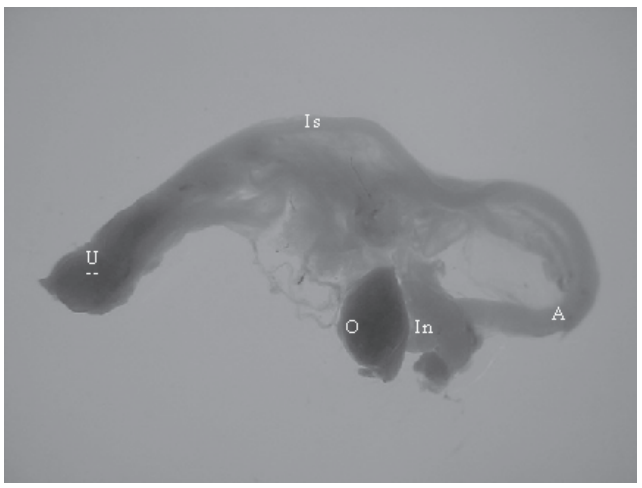

Figura 1 - Fotografia digitalizada de parte do sistema genital feminino da cutia (Dasyprocta aguti). Observa-se as regiões da tuba uterina: Infundíbulo (In), ampola (A) e Istmo (Is). Vê-se ainda, ovário $(\mathrm{O})$ e parte do corno uterino $(\mathrm{U})$
A parede da tuba uterina encontra-se organizada em três camadas, vistas ao microscópio de luz: a mucosa, a muscular de úsculo liso e a camada serosa, externamente, Matos e Vale ${ }^{12}$ milarmente o que é descrito aliteratura $2,3,5,6,7,8,10,13,14,15,16$.

Evidencia-se, na cutia, a mucosaevestida por epitélio simples colunar com células ciliadas e não ciliadas, com características de células secretoras, e apresentando grande quantidade de pregas em diferentes níveis (Figura 2). O pregueamento mucoso é mais proeminente nas porções do infundíbulo e da ampola (Figuras 2 e 3). No istmo, observa-se áreas com células epiteliais baixas variando entre cúbicas e pavimentosas. Nessa região as células ciliadas reduzem em quantidade, e aumenta o número de células não ciliadas. Essas observações se assemelham as descritas por ${ }^{2,3,5,13}$. Ainda, de acordo com Felipe, Cabodevila e Callejas ${ }^{14}$ em estudos sobre a junção utero-tubárica do Myocastor coypus que apontam, para o segmento caudal do istmo, de 3 a 4 pregas mucosas baixas e sem ramificações. Entretanto, nossos achados não podem ser comparados com os destes últimos autores no relativo ao número de pregas mucosas, uma vez que, neste estudo, não foi realizada a contagem das

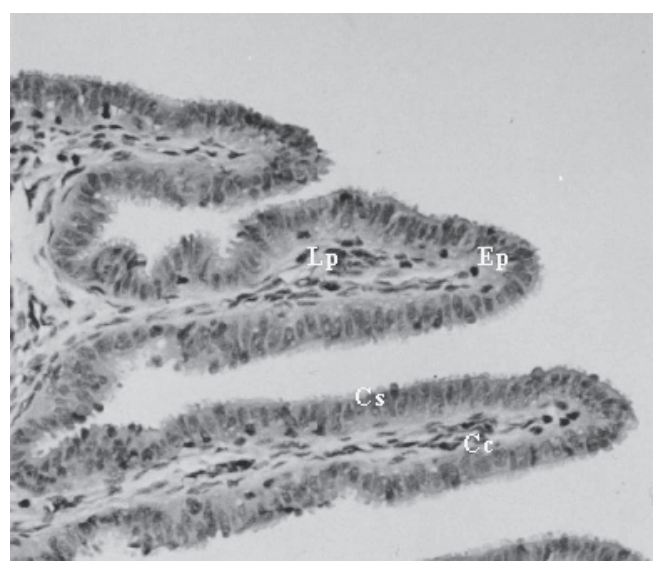

Figura 2 - Fotomicrografia da porção cranial (infundíbulo) da tuba uterina da cutia, em corte transversal onde se nota: pregas da mucosa com o epitélio simples colunar (Ep) com células ciliadas (Cc) e não ciliadas secretoras (Cs) e a lâmina própria (Lp). ( $\pm 400 x$ - hematoxilina-eosina) 


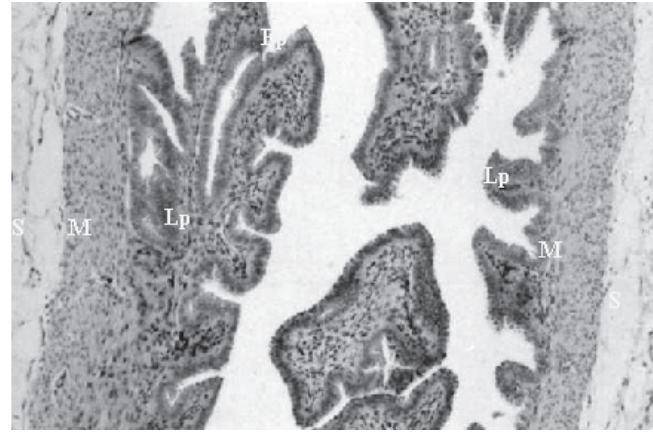

Figura 3 - Fotomicrografia da porção média (ampola) da tuba uterina da cutia, em corte transversal, mostrando: lúmen tubular (L); epitélio de revestimento da mucosa (Ep); lâmina própria (Lp); camada muscular circular interna e longitudinal externa (M) e serosa (S). ( $\pm 200 x$ - hematoxilina-eosina)

mesmas.

Foi verificado que a luz do órgão, nas porções cranial e média, (Figura 3) apresentase bem maior em diâmetro porém, mais irregular que na porção caudal (Figura 4). A lâmina própria, formada de tecido conjuntivo frouxo, é desprovida de glândulas, e na região da ampola, torna-se mais estreita e bastante celularizada, confirmando também as descrições da literatura consultada.

Em relação a camada muscular, mostra-se constituída por fibras musculares lisas dispostas em uma subcamada circular interna e outra longitudinal externa, (Figura 3) características similares às assinaladas $\operatorname{por}^{2,5,7,8}$. Já, Dellman e Brown ${ }^{3}$ acrescentam, também, alguns feixes musculares oblíquos.

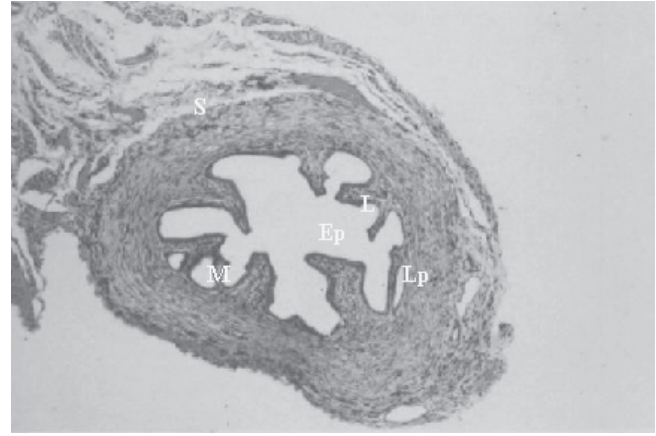

Figura 4 - Fotomicrografia da porção caudal (istmo) da tuba uterina da cutia, em corte transversal, exibindo: lúmen tubular (L); epitélio de revestimento da mucosa (Ep); lâmina própria (Lp); camada muscular circular (M); serosa $(\mathrm{S}) .( \pm 100 \mathrm{x}$ - hematoxilina-eosina)

Na região do istmo verifica-se apenas fibras musculares dispostas circularmente, (Figura 4). Almeida et al. ${ }^{10}$ afirmam que no gerbil da Mongólia, a túnica muscular apresenta duas camadas sem limites distintos.

Ainda, relativamente à camada serosa, as observações na cutia são semelhantes as apresentadas na literatura consultada para a maioria das espécies domésticas, ou seja, constituída de tecido conjuntivo frouxo revestido por epitélio simples pavimentoso (mesotélio), ricamente vascularizada (Figura 4).

Com base nesta caracterização, podese concluir que as tubas uterinas da cutia guardam muita semelhança com as dos demais mamíferos domésticos e silvestres, especialmente, roedores.

\section{Morphological aspects of the uterine tube in agouti (Dasyprocta aguti, Mammalia: Rodentia)}

\section{Abstract}

It was analysed the uterine tube structure in Agouti. We have used three adult females, caming from Wild Animals Preservation and Study Nucleous of "Universidade Federal do Piauí". Soon after anaesthesia and euthanasia we got collected uterine tube fragments from cranial, medial and caudal regions. The cuts of 3 to $5 \mathrm{~m}$ were stained with HE, and analysed and photographed with a light microscope. We could observed that the uterine tubes have three distincts stratums: mucous membrane, muscular and serous with histologicals differences that characterize the infundibulum, ampulla
Key-words: Histology. Uterine tube. Agouti. Rodents. 
and isthmus regions. The uterine tube light is irregular, on cranial and medium portions. It is bigger and irregular than caudal portion. The mucous membrane is coat with simple columnar epithelium with ciliar and nonciliar cells. The own lamina, formed of slack conjunctive tissue, without glands, on ampulla region, become small and we can observe many cells. On isthmus mucous we observe ephithelial tissue with low cells. The muscular, constituted of smooth fibres, that is observed like a circular and longitudinal stratum, and the serous stratum full of vessels. Histologically, the uterine tube in Agouti is similar to the others domestic and wild animals.

\section{Referências}

1 NOGUEIRA NETO, P. A criação de animais indígenas vertebrados. São Paulo: Tecnapis, 1973. 327 p.

2 BANKS, W. J. Histologia Veterinária Aplicada. 2. ed. São Paulo: Manole, 1991. 631 p.

3 DELLMANN, H. D.; BROWN, E. M. Histologia veterinária. Rio de Janeiro: Guanabara Koogan, 1982. $397 \mathrm{p}$.

4 DYCE, K. M.; SACK, W. O.; WENSING, C. J. G. Tratado de anatomia veterinária. 2. ed. Rio de Janeiro: Guanabara Koogan, 1997. $663 \mathrm{p}$

5 HAFEZ, E. S. E. Reprodução animal. 4. ed. São Paulo: Manole, 1995. $582 \mathrm{p}$

6 WALTER, C. A. et al. Vascularização arterial e estrutura das tubas uterinas em caprinos sem raça definida. Braz. J. Vet. Res. Anim. Sci.,v.38, n.3, p.106-109, 2001.

7 GARTNER, L. P.; HIATT, J. L. Tratado de Histologia. Rio de Janeiro: Guanabara Koogan, 1997. 426 p.

8 JUNQUEIRA, L. C. U.; CARNEIRO, J. Histologia Básica. 9. ed. Rio de Janeiro: Guanabara, 2001. 427 p.

9 WEIR, B. J.; ROWLANDS, I. W. Functional anatomy of the hystricomorph ovary.Symp. Zool. Soc. Lond., v. 34, p. 303-332, 1974

10 ALMEIDA, C. C. D. et al. Estrous cycle, anatomy and histology of the uterine tube of the Mongolian gerbil (Meriones unguiculatus). Rev. Chil. Anat., v. 19, n. 2, p. 191-196, 2001.

11 ARAÚJO, W. R. et al. Macroscopic and Biometric Parameters of the Feminine Genital Organs of Agouti's ( Dasyprocta aguti). Rev. Bras. Reprod. Anim., n. 5, out. 2002. Supplement.

12 GUIMARÃES, D. A.; MATOS, E.; VALE, W. G. Estudo morfológico do sistema genital feminino de cutia (Dasyprocta prymnolopha, Rodentia: Cavidae). Revista Brasileira de Ciências Morfológicas, v. 11, n. 2, p. 167$171,1994$.

13 FELIPE, A. E.; CALLEJAS, S. S.; CABODEVILA, J. A. Anatomichistological characcteristics of female genital tubular organs of the south american nutria (Myocastor coypus). Anatomical Histological Embriologic, v. 27, p. 245-250, 1998.

14 FELIPE, A. E.; CABODEVILA, J. A. ; CALLEJAS, S. S. Morfología de la unión útero-tubárica en Myocastor coipus (COIPO). Rev. Chil. Anat. v. 20, n. 2, p. 139-144, 2002.

15 GONÇALVES, R. S. et al. Morphological study of ephitelial cells from bovine uterine tube in vitro $\mathrm{e}$ in situ. Braz. J. Morphol. Sci., v. 16, n. 1, p. 91-96, 1999.

16 SANTOS, T. C. Morfologia dos ovários, tubas uterinas e útero em catetos (Tayassu tajacu - Linnaeus, 1758) e queixadas ( Tayassu pecari - Link, 1758). 1999, $148 \mathrm{f}$. Dissertação (Mestrado) - Faculdade de Medicina Veterinária e Zootecnia, Universidade de São Paulo, São Paulo, 1999.

17 SILVA, C. L.; PERDOMO, F. Alguns aspectos anatômicos e histológicos del sistema genital femenino del chiguiri (Hidrochoerus hidrochaeris). Revista da Faculdade de Ciências Veterinárias da Universidade Central da Venezuela, v. 30, n. 18, p. 89-97, 1983. 